\title{
A Study of $\mathrm{Fe}_{3} \mathrm{O}_{4} @$ Zigzag, @Armchair and @Chiral SWCNTs and $\alpha \& \gamma$ Cyclodextrins
}

\author{
SOMAYEH KHOSRAVI \\ Department of Chemistry, Science and Research Branch, Islamic Azad University, Tehran, Iran. \\ ${ }^{*}$ Corresponding author E-mail:S.khosravi1986@gmail.com \\ http://dx.doi.org/10.13005/ojc/320421
}

(Received: June 02, 2016; Accepted: July 28, 2016)

\begin{abstract}
$\mathrm{Fe}_{3} \mathrm{O}_{4}$ is used as a catalyst in the Haber process and in the water gas shift reaction. In this work we have investigated the physical and chemical properties of $\mathrm{Fe}_{3} \mathrm{O}_{4} @$ Zigzag, @ Armchair and @Chiral SWCNTs compare to $\mathrm{Fe}_{3} \mathrm{O}_{4} @ \alpha \& \gamma$-Cyclodextrin in view point of chemical reaction and sensitizes. The electrical properties such as NMR Shielding, electron densities, energy densities , potential energy densities, ELF, LOL, ellipticity of electron density, eta index and ECP for $\mathrm{Fe}_{3} \mathrm{O}_{4} @$ -Cyclodextrin shell and $\mathrm{Fe}_{3} \mathrm{O}_{4} @$ Zigzag, @ Armchair and @ Chiral SWCNTs have been calculated for the simulations. Our Calculation indicate that the $\mathrm{Fe}_{3} \mathrm{O}_{4} @(7,7)$ and $\mathrm{Fe}_{3} \mathrm{O}_{4} @(10,5)$ and $\mathrm{Fe}_{3} \mathrm{O}_{4}$ $@(9,0)$ have physical and chemical properties close to $\mathrm{Fe}_{3} \mathrm{O}_{4} @-C y c l o d e x t r i n$ and as well as the $\mathrm{Fe}_{3} \mathrm{O}_{4} @(8,8)$ and $\mathrm{Fe}_{3} \mathrm{O}_{4} @(11,6)$ and $\mathrm{Fe}_{3} \mathrm{O}_{4} @(10,0)$ are close to $\mathrm{Fe}_{3} \mathrm{O}_{4} @-C y c l o d e x t r i n$.
\end{abstract}

Keywords: $\mathrm{Fe}_{3} \mathrm{O}_{4}$, Nano-Particles, electron density, SWCNTs, Cyclodextrin $(\alpha \& \gamma)$.

\section{INTRODUCTION}

$\mathrm{Fe}_{3} \mathrm{O}_{4}$ nanoparticles (MNPs) are one of the most intensively studied magnetic nanoparticles and can be applied in a variety of areas, ranging from drug delivery ${ }^{1}$ and bio-sensing ${ }^{2}$, dynamic sealing ${ }^{3}$, and cell labeling ${ }^{4}$ to magnetic resonance imaging ${ }^{5}$.

$\mathrm{Fe}_{3} \mathrm{O}_{4}$ is ferromagnetic with a curie temperature of $858 \mathrm{~K}$ and The ferromagnetism of $\mathrm{Fe}_{3} \mathrm{O}_{4}$ arises because the electron spins of the $\mathrm{Fe}^{\prime \prime}$ and Fe $\mathrm{e}^{\mathrm{II}}$ ions in the octahedral sites are coupled and the spins of the Fe $\mathrm{e}^{\mathrm{III}}$ ions in the tetrahedral sites are coupled but anti-parallel to the former ${ }^{6,7}$.

$\mathrm{Fe}_{3} \mathrm{O}_{4}$ is used as a catalyst in the Haber process and in the water gas shift reaction ${ }^{7,8}$.

Moreover, MNPs are well suited for target capturing, enrichment, and isolation ${ }^{9}$. Accordingly, they can be used for isolating cells ${ }^{10}$ and bacteria ${ }^{11}$ and for removing environmental toxins such as heavy metals and chemical waste ${ }^{12}$. 
The latter uses an HTS (high temperature shift catalyst) of iron oxide stabilized by chromium oxide ${ }^{6-8}$. This iron-chrome catalyst is reduced at reactor start up to generate $\mathrm{Fe}_{3} \mathrm{O}_{4}$ from á- $\mathrm{Fe}_{2} \mathrm{O}_{3}$ and $\mathrm{Cr}_{2} \mathrm{O}_{3}$ to $\mathrm{CrO}_{3}{ }^{5}$. $\mathrm{Fe}_{3} \mathrm{O}_{4}$ is an electrical conductor with conductivity significantly higher than $\mathrm{Fe}_{2} \mathrm{O}_{3}$, and this is ascribed to electron exchange between the Fe" and $\mathrm{Fe}^{\mathrm{III}}$ centers ${ }^{6-9}$.

Magnetite $\left(\mathrm{Fe}_{3} \mathrm{O}_{4}\right)$ is the earliest discovered magnet which crystallizes in the inverse cubic spinel structure. Each cubic spinel cell contains eight interpenetrating oxygen and the tetrahedral sites, occupied by one-third of the iron atoms, form a diamond structure. The remaining $\mathrm{Fe}$ atoms are located at the octahedral sites with the nearestneighbor atoms lined up as strings along six different [110] directions. In other words $\mathrm{Fe}_{3} \mathrm{O}_{4}$ consists of a cubic close packed array of oxide ions where all of the $\mathrm{Fe}^{2+}$ ions occupy half of the octahedral sites and the $\mathrm{Fe}^{3+}$ are split evenly across the remaining octahedral sites and the tetrahedral sites ${ }^{6,13}$, and 14 .

Nano sized magnetic particles are considered potential adsorbents for aqueous heavy metals due to their high surface area and the unique advantage of easy separation under external magnetic fields ${ }^{15-19}$. To further facilitate the adsorption affinity, surface modification, including physical coating and covalent binding, has often been explored to enable specific metal complexation ${ }^{20-25}$. For example, covalent attachment of carboxylic groups to the surface of magnetic nanoparticles was achieved by reacting hematite with 11-undecanoic acid, and the resulting material showed marked ability in adsorbing $\mathrm{Cd}$ (II) ${ }^{20}$. The chitosan-coated $\mathrm{Fe}_{3} \mathrm{O}_{4}$ nanoparticles were reported to be efficient for the removal of $\mathrm{Cu}$ (II) ions ${ }^{22}$. Humic-acid-coated $\mathrm{Fe}_{3} \mathrm{O}_{4}$ nanoparticles prepared by the co-precipitation method were found to effectively sorb $\mathrm{Hg}$ (II), $\mathrm{Pb}$ (II), $\mathrm{Cd}$ (II), and $\mathrm{Cu}$ (II) from water ${ }^{23}$. The thiol groups on the surfaces of Di-Mercapto-succinic acidcoated $\mathrm{Fe}_{3} \mathrm{O}_{4}$ nanoparticles also acted as binding ligands for $\mathrm{Hg}, \mathrm{Ag}, \mathrm{Pb}, \mathrm{Cd}$, and $\mathrm{Tl}$ metal ions ${ }^{24}$. Recently, a magnetic nano-adsorbent prepared by coating a magnetite core with chitosan, followed by carboxylation with a keto-glutamic acid, was used to remove $\mathrm{Cu}$ (II) ions from aqueous solution ${ }^{25}$.
$\mathrm{SiO}^{2}$ is stable under acidic conditions and inert to redox reactions, as compared with the organic coating materials, and hence functions as an ideal shell composite to protect the inner magnetite core $^{26-28}$. Silica-coated core-shell magnetite nanoparticles, i.e., $\mathrm{Fe}_{3} \mathrm{O}_{4} @ \mathrm{SiO}^{2}$, have recently been investigated for potential biomedical applications ${ }^{27,28}$. Additionally, the $\mathrm{SiO}^{2}$ coating shell has an abundance of surface hydroxyl groups, which offers ease of functionalization of magnetite nanoparticles.

Cyclodextrins, cyclic oligosaccharides obtained from the degradation of starch by Bacillus macerans, were first isolated in the late nineteenth century ${ }^{29}$. Their ability to form inclusion complexes with suitable organic molecules was discovered soon thereafter ${ }^{30}$. With the development of the field of Supramolecular Chemistry, their complexation properties have been extensively studied ${ }^{31}$ Applications for cyclodextrins and their derivatives are sought in various areas of chemistry, including the sensing of organic molecules ${ }^{32}$.

Carbon nanotube (CNT) is a representative nano-material. CNT is a cylindrically shaped carbon material with a nano-metric-level diameter ${ }^{33}$.Its structure, which is in the form of a hexagonal mesh, resembles a graphite sheet and it carries a carbon atom located on the vertex of each mesh. The sheet has rolled and its two edges have connected seamlessly ${ }^{33,34}$.

Although it is a commonplace material using in pencil leads, its unique structure causes it to present characteristics that had not found with any other materials. CNT can be classified into single-wall CNT, double-wall CNT and multi-wall CNT according to the number of layers of the rolled graphite. The type attracting most attention is the single-wall CNT, which has a diameter deserving the name of "nanotube" of 0.4 to 2 nanometers. The length is usually in the order of microns, but single-wall CNT with a length in the order of centimeters has recently released.

SWCNTs have considered as the leading candidate for nano-device applications because of their one-dimensional electronic bond structure, molecular size, and biocompatibility, controllable property of conducting electrical current and reversible 
response to biological reagents hence SWCNTs make possible bonding to polymers and biological systems such as DNA and carbohydrates.

\section{Theoretical background}

\section{Electron density profile models}

The electron density has been defined as

$$
\rho(r)=\eta_{i}\left|\varphi_{i}(r)\right|^{2}=\sum_{i} \eta_{i}\left|\sum_{l} C_{l, i} \chi_{i}(r)\right| z_{i}
$$

Where $\eta_{i}$ is occupation number of orbital (i), $\varphi$ is orbital wave function, $\mathrm{c}$ is basis function and $C$ is coefficient matrix, the element of $i_{\text {th }}$ row $j_{\text {th }}$ column corresponds to the expansion coefficient of orbital $j$ respect to basis function $i$. Atomic unit for electron density can be explicitly written as e/Bohr ${ }^{3}$.

$$
\nabla \rho(r)=\left[\left(\frac{\partial \rho(r)}{\partial(x)}\right)^{2}+\left(\frac{\partial \rho(r)}{\partial(y)}\right)^{2}+\left(\frac{\partial \rho(r)}{\partial(z)}\right)^{2}\right]^{\frac{1}{2}}
$$

$$
\nabla^{2} \rho(r)=\frac{\partial^{2} \rho(r)}{\partial x^{2}}+\frac{\partial^{2} \rho(r)}{\partial y^{2}}+\frac{\partial^{2} \rho(r)}{\partial z^{2}}
$$

The positive and negative value of this function correspond to electron density is locally depleted and locally concentrated respectively. The relationships between $\nabla^{2} \rho$ and valence shell electron pair repulsion (VSEPR) model, chemical bond type, electron localization and chemical reactivity have

\begin{tabular}{|c|c|c|c|c|c|c|}
\hline $\begin{array}{l}\text { Atom } \\
\text { number }\end{array}$ & $\begin{array}{l}\text { Density of all } \\
\text { electron } 10^{-3}\end{array}$ & $\begin{array}{l}\text { Density of } \\
\text { alpha } 10^{-3}\end{array}$ & $\begin{array}{l}\text { Density of } \\
\text { Beta } 10^{-3}\end{array}$ & $\begin{array}{l}\text { Spin } \\
\text { Density }\end{array}$ & $\begin{array}{c}\text { Lagrangian kinetic } \\
{[G(r)] \text { energy }\left(10^{-3}\right)}\end{array}$ & $\begin{array}{c}\text { Hamiltonian } \\
\text { kinetic }[K(r)] \\
\text { energy }\left(10^{-2}\right)\end{array}$ \\
\hline $\mathrm{Fe}(1)$ & 0.14 & 0.07 & 0.07 & 0.0 & 0.22 & 0.32 \\
\hline $\mathrm{Fe}(2)$ & 0.26 & 0.13 & 0.13 & 0.0 & 0.26 & 0.56 \\
\hline $\mathrm{Fe}(3)$ & 0.32 & 0.16 & 0.16 & 0.0 & 0.11 & 0.24 \\
\hline $\mathrm{O}(1)$ & 0.24 & 0.12 & 0.12 & 0.0 & 0.28 & -0.12 \\
\hline $\mathrm{O}(2)$ & 0.18 & 0.09 & 0.09 & 0.0 & 0.31 & -0.22 \\
\hline $\mathrm{O}(3)$ & 0.40 & 0.2 & 0.2 & 0.0 & 0.27 & -0.11 \\
\hline $\mathrm{O}(4)$ & 0.30 & 0.15 & 0.15 & 0.0 & 0.11 & -0.22 \\
\hline
\end{tabular}
been built by Bader $^{38}$.

Table1: All Electron Densities of non-bonded interactions for $\mathrm{Fe}_{3} \mathrm{O}_{4}-$ Cyclodextrin $(\gamma)$

Table 2: Laplacian, ELF, LOL and Local information entropy of non-bonded interactions for Cyclodextrin $(\gamma)$

\begin{tabular}{lcccccc}
\hline $\begin{array}{l}\text { Atom } \\
\text { number }\end{array}$ & $\begin{array}{c}\text { Laplacian of } \\
\text { electron } \\
\text { density } \\
\left(\mathbf{1 0 ^ { - 1 }}\right)\end{array}$ & $\begin{array}{c}\text { Electron } \\
\text { localization } \\
\text { function } \\
\text { ELF }\left(\mathbf{1 0}^{-3}\right)\end{array}$ & $\begin{array}{c}\text { Localized } \\
\text { orbital locator } \\
\mathbf{( L O L )} \\
\mathbf{( 1 0 ^ { - 1 } )}\end{array}$ & $\begin{array}{c}\text { Local } \\
\text { information } \\
\text { entropy } \\
\mathbf{( 1 0 ^ { - 4 } )}\end{array}$ & $\begin{array}{c}\text { Reduced } \\
\text { density } \\
\text { gradient(RDG) } \\
\left(\mathbf{1 0 ^ { + 1 } )}\right.\end{array}$ & $\begin{array}{c}\text { Average } \\
\text { local } \\
\text { ionization } \\
\text { energy }\end{array}$ \\
\hline $\mathrm{Fe}(1)$ & -0.15 & 0.60 & 0.18 & 0.17 & 0.39 & 0.32 \\
$\mathrm{Fe}(2)$ & -0.16 & 0.42 & 0.28 & 0.19 & 0.41 & 0.39 \\
$\mathrm{Fe}(3)$ & -0.20 & 0.32 & 0.18 & 0.41 & 0.52 & 0.50 \\
$\mathrm{O}(1)$ & 0.38 & 0.32 & 0.24 & 0.18 & 0.44 & 0.34 \\
$\mathrm{O}(2)$ & 0.41 & 0.22 & 0.15 & 0.29 & 0.16 & 0.16 \\
$\mathrm{O}(3)$ & 0.35 & 0.26 & 0.34 & 0.31 & 0.47 & 0.83 \\
$\mathrm{O}(4)$ & 0.34 & 0.33 & 0.22 & 0.25 & 0.24 & 0.20 \\
\hline
\end{tabular}


Hamiltonian kinetic energy density $\mathbf{K}(\mathbf{r})$

The kinetic energy density is not uniquely defined, since the expected value of kinetic energy operator

$$
<\varphi\left|-\left(\frac{1}{2}\right) \nabla^{2}\right| \varphi>
$$

can be recovered by integrating kinetic energy density from alternative definitions. One of commonly used definition is:

$$
k(r)=-\frac{1}{2} \Sigma_{i} \eta_{i} \varphi_{i}^{*}(r) \nabla^{2} \varphi_{i}(r)
$$

Relative to $K(\mathbf{r})$, the local kinetic energy definition given below guarantee positivizes everywhere; hence the physical meaning is clearer and is more commonly used.

Table 3: Lambada2, Wave function value, Ellipticity of electron density and Eta index of non-bonded interactions for Cyclodextrin $(\gamma)$

\begin{tabular}{lcccccc}
\hline $\begin{array}{c}\text { Atom } \\
\text { number }\end{array}$ & $\begin{array}{c}\text { Lambada2 } \\
\left(\mathbf{1 0}^{-3}\right)\end{array}$ & $\begin{array}{c}\text { Wave function } \\
\text { value }\left(\mathbf{1 0}^{-3}\right)\end{array}$ & $\begin{array}{c}\text { Ellipticity of } \\
\text { electron density }\end{array}$ & $\begin{array}{c}\text { Eta index } \\
\text { (n) }\end{array}$ & $\begin{array}{c}\text { ESP from } \\
\text { nuclear } \\
\left.\text { charge (10 } \mathbf{H}^{4}\right)\end{array}$ & $\begin{array}{c}\text { ESP from } \\
\text { electron } \\
\text { charge }\left(\mathbf{1 0}^{2}\right)\end{array}$ \\
\hline $\mathrm{Fe}(1)$ & -0.12 & 0.41 & 0.40 & -3.15 & 0.10 & -0.41 \\
$\mathrm{Fe}(2)$ & -0.14 & 0.89 & 0.40 & -3.65 & 0.10 & -0.41 \\
$\mathrm{Fe}(3)$ & -0.14 & 0.62 & 0.33 & 1.77 & 0.10 & -0.42 \\
$\mathrm{O}(1)$ & 0.35 & 0.31 & -0.44 & 1.47 & 0.11 & -0.43 \\
$\mathrm{O}(2)$ & 0.15 & -0.41 & -0.27 & 0.90 & 0.11 & -0.41 \\
$\mathrm{O}(3)$ & 0.31 & 0.35 & -0.43 & 0.68 & 0.11 & -0.42 \\
$\mathrm{O}(4)$ & 0.28 & -0.38 & -0.27 & 0.66 & 0.15 & -0.41 \\
\hline
\end{tabular}

Table 4: All Electron Densities of non-bonded interactions for $\mathrm{Fe}_{3} \mathrm{O}_{4} @(11,6)$ SWCNTs

\begin{tabular}{lccccccc}
\hline $\begin{array}{l}\text { Atom } \\
\text { number }\end{array}$ & $\begin{array}{c}\text { Density of } \\
\text { all electron } \\
\mathbf{1 0}^{-3}\end{array}$ & $\begin{array}{c}\text { Density of } \\
\text { alpha } \\
\mathbf{1 0}^{-3}\end{array}$ & $\begin{array}{c}\text { Density of } \\
\text { Beta } \\
\mathbf{1 0}^{-3}\end{array}$ & $\begin{array}{c}\text { Spin } \\
\text { Density }\end{array}$ & $\begin{array}{c}\text { Lagrangian } \\
\text { kinetic } \\
{[\mathrm{G}(\mathbf{r})] \text { energy }}\end{array}$ & $\begin{array}{c}\text { Hamiltonian } \\
\text { kinetic [K(r)] } \\
\text { energy }\end{array}$ & $\begin{array}{c}\text { Energy } \\
\text { Density } \\
{[\mathrm{E}(\mathbf{r})]}\end{array}$ \\
\hline $\mathrm{Fe}(1)$ & 0.42 & 0.21 & 0.21 & 0.0 & 0.51 & 0.55 & -0.41 \\
$\mathrm{Fe}(2)$ & 0.62 & 0.31 & 0.31 & 0.0 & 0.25 & 0.24 & -0.23 \\
$\mathrm{Fe}(3)$ & 0.78 & 0.39 & 0.39 & 0.0 & 0.22 & 0.23 & -0.21 \\
\hline
\end{tabular}

Table 5: Laplacian, ELF, LOL and Local information entropy of non-bonded interactions for $\mathrm{Fe}_{3} \mathrm{O}_{4} @(8,8)$ SWCNTs

\begin{tabular}{lccccccc}
\hline $\begin{array}{l}\text { Atom } \\
\text { number }\end{array}$ & $\begin{array}{c}\text { Laplacian of } \\
\text { electron } \\
\text { density } \\
\mathbf{1 0}^{-1}\end{array}$ & $\begin{array}{c}\text { Electron } \\
\text { localization } \\
\text { function } \\
\text { (ELF) } \mathbf{( \mathbf { 1 0 } ^ { - 3 } )}\end{array}$ & $\begin{array}{c}\text { Localized } \\
\text { orbital } \\
\text { locator (LOL) } \\
\mathbf{1 0}^{-1}\end{array}$ & $\begin{array}{c}\text { Local } \\
\text { information } \\
\text { entropy } \\
\mathbf{1 0}^{-4}\end{array}$ & $\begin{array}{c}\text { Reduced } \\
\text { density } \\
\text { gradient } \\
\text { (RDG) } \mathbf{1 0}^{+1}\end{array}$ & $\begin{array}{c}\text { Average } \\
\text { local } \\
\text { ionization } \\
\text { energy }\end{array}$ & $\begin{array}{c}\text { ESP from } \\
\text { electron } \\
\text { charge } \\
\mathbf{1 0}^{\mathbf{2}}\end{array}$ \\
\hline $\mathrm{Fe}(1)$ & -0.08 & 0.31 & 0.22 & 0.20 & 0.18 & 0.49 & -0.68 \\
$\mathrm{Fe}(2)$ & -0.08 & 0.30 & 0.12 & 0.14 & 0.35 & 0.51 & -0.67 \\
$\mathrm{Fe}(3)$ & -0.09 & 0.48 & 0.12 & 0.21 & 0.22 & 0.33 & -0.68 \\
\hline
\end{tabular}


The Lagrangian kinetic energy density, "G(r)" is also known as positive definite kinetic energy density.

$$
\begin{gathered}
G(r)=\frac{1}{2} \sum_{i} \eta_{i} \mid \nabla\left(\left.\varphi_{i}\right|^{2}=\frac{1}{2} \sum_{i} \eta_{i}\left\{\left[\left(\frac{\partial \varphi_{i}(r)}{\partial(x)}\right)^{2}\right.\right.\right. \\
\left.\left.+\left(\frac{\partial \varphi_{i}(r)}{\partial(y)}\right)^{2}+\left(\frac{\partial \varphi_{i}(r)}{\partial(z)}\right)^{2}\right]\right\}
\end{gathered}
$$

$K(r)$ and $G(r)$ are directly related by Laplacian of electron density

$$
\frac{1}{4} \nabla^{2} \rho(r)=G(r)-K(r)
$$

\section{Electron localization function (ELF)}

Becke and Edgecombe noted that spherically averaged likespin conditional pair probability has direct correlation with the Fermi hole and then suggested electron localization function (ELF) [39].

$$
\operatorname{ELF}(\mathrm{r})=\frac{1}{1+\left[D(r) / D_{0(r)}\right]^{2}}
$$

where

$\mathrm{D}(\mathrm{r})=\frac{1}{2} \sum_{i} \eta_{i}\left|\nabla \varphi_{i}\right|^{2}-\frac{1}{8}\left[\frac{\left.|| \nabla \rho_{\alpha}\right|^{2}}{\rho_{\alpha}(r)}+\frac{\left.|| \nabla \rho_{\beta}\right|^{2}}{\beta(r)}\right]$

and

$$
D_{0(r)}=\frac{3}{10}\left(6 \pi^{2}\right)^{\frac{2}{3}}\left[\rho_{\alpha}(r)^{\frac{5}{3}}+\rho_{\beta}(r)^{\frac{5}{3}}\right]
$$

for close-shell system, since $\rho_{\alpha}(r)=\rho_{\beta}(r)=\frac{1}{2} \rho, D$ and $D 0$ terms can be simplified as

$$
\begin{aligned}
& \mathrm{D}(\mathrm{r})=\frac{1}{2} \sum_{i} \eta_{i}\left|\nabla \varphi_{i}\right|^{2}-\frac{1}{8}\left[\frac{\left|\nabla_{\rho}\right|^{2}}{\rho(r)}\right] \\
& D_{0(r)}=\frac{3}{10}\left(3 \pi^{2}\right)^{\frac{2}{3}} \rho(r)^{\frac{5}{3}}
\end{aligned}
$$

Savin et al. have reinterpreted ELF in the view of kinetic energy, ${ }^{40}$ which makes ELF also meaningful for Kohn-Sham DFT wave-function or even post-HF wave-function. They indicated that $D(\mathbf{r})$ reveals the excess kinetic energy density caused by Pauli repulsion, while $D O(\mathbf{r})$ can be considered as Thomas-Fermi kinetic energy density ${ }^{41}$.

Localized orbital locator (LOL) is another function for locating high localization regions likewise ELF, defined by Schmider and Becke in the paper $^{42,43}$.

$$
\operatorname{LOL}(r)=\frac{\tau(r)}{1+\tau(r)}
$$

where

$$
(r)=\frac{D_{0}(r)}{\frac{1}{2} \sum_{i} \eta_{i}\left|\nabla \varphi_{i}\right|^{2}}
$$

$D_{0}(r)$ for spin-polarized system and closeshell system are defined in the same way as in ELF43.

This work has been studied based some previous works ${ }^{44-167}$ and has compared with the experimental data.

Table 6: Lambada2, Wave function value, Ellipticity of electron density and Eta index of non-bonded interactions for $\mathrm{Fe}_{3} \mathrm{O}_{4} @(10,0)$ SWCNTs

\begin{tabular}{lcccc}
\hline $\begin{array}{l}\text { Atom } \\
\text { (number) }\end{array}$ & $\begin{array}{c}\text { Lambada2 } \\
\left(\mathbf{1 0}^{-3}\right)\end{array}$ & $\begin{array}{c}\text { Wave function value } \\
\left(\mathbf{1 0}^{-4}\right)\end{array}$ & $\begin{array}{c}\text { Ellipticity of electron } \\
\text { density }\end{array}$ & Eta index \\
\hline $\mathrm{Fe}(1)$ & -0.31 & 0.14 & 0.98 & 1.2 \\
$\mathrm{Fe}(2)$ & -0.54 & 0.15 & 0.92 & 2.1 \\
$\mathrm{Fe}(3)$ & 0.23 & -0.34 & 0.90 & 0.5 \\
\hline
\end{tabular}



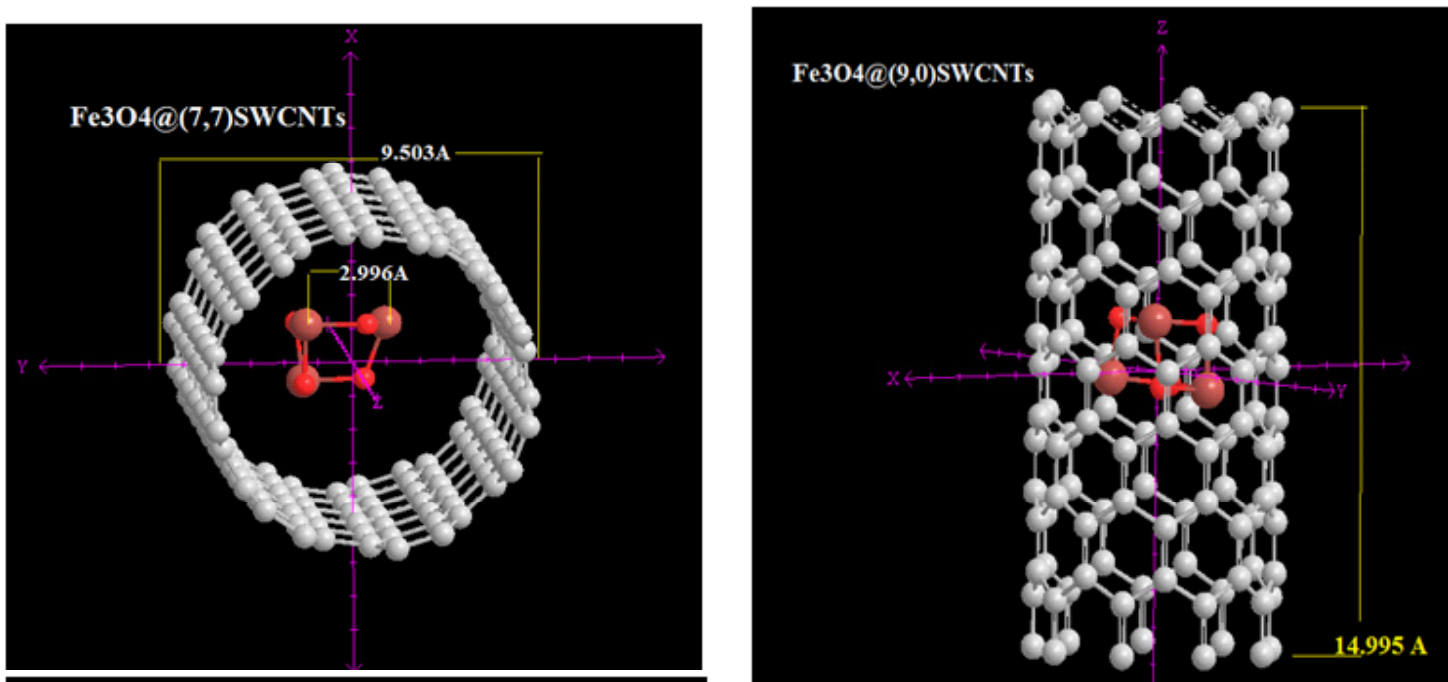

Fe304@(8,8)SWCNTs
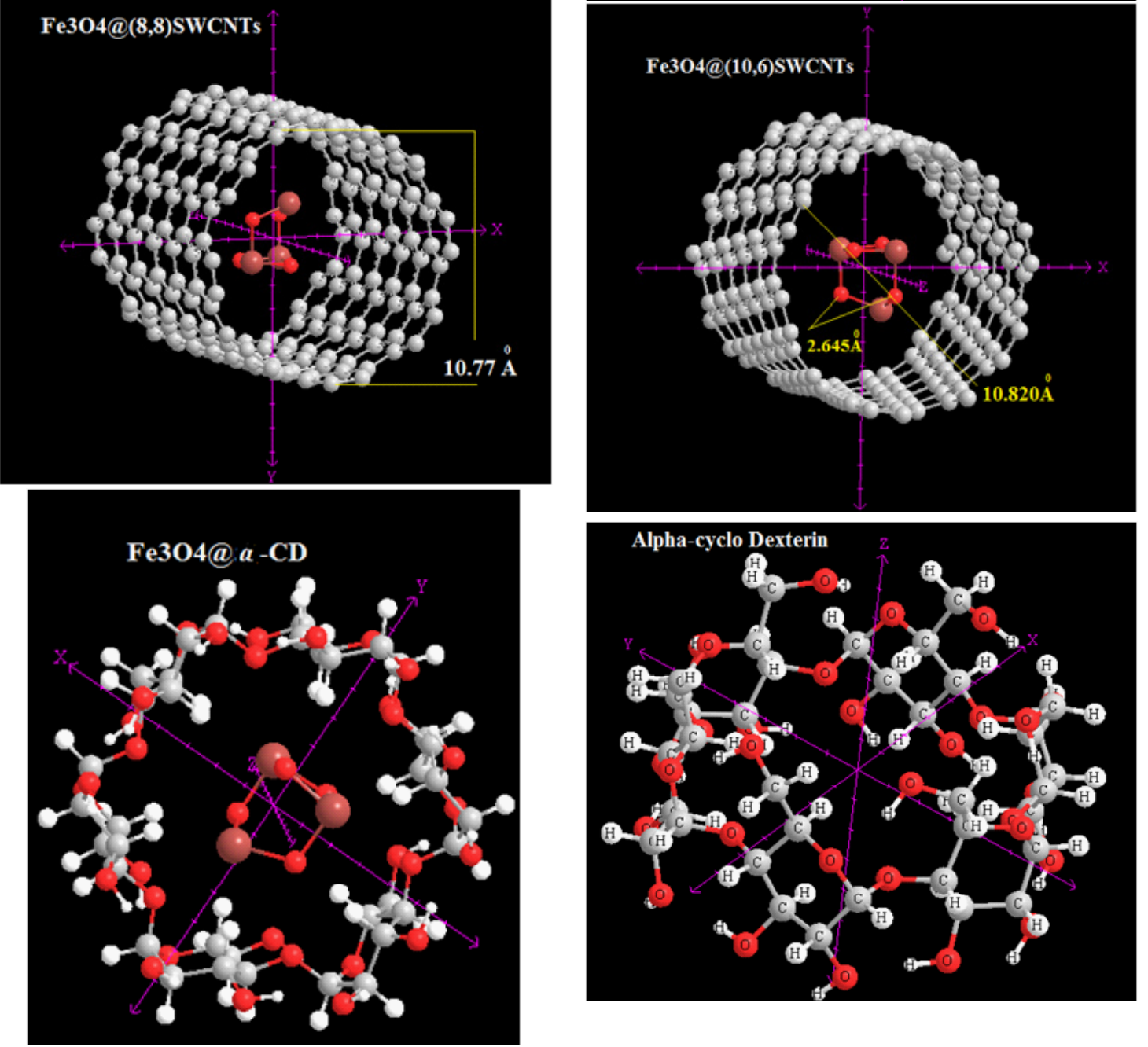

Fig.1: Optimized $\mathrm{Fe}_{3} \mathrm{O}_{4} @$ various nanotubes and cyclodexterin 


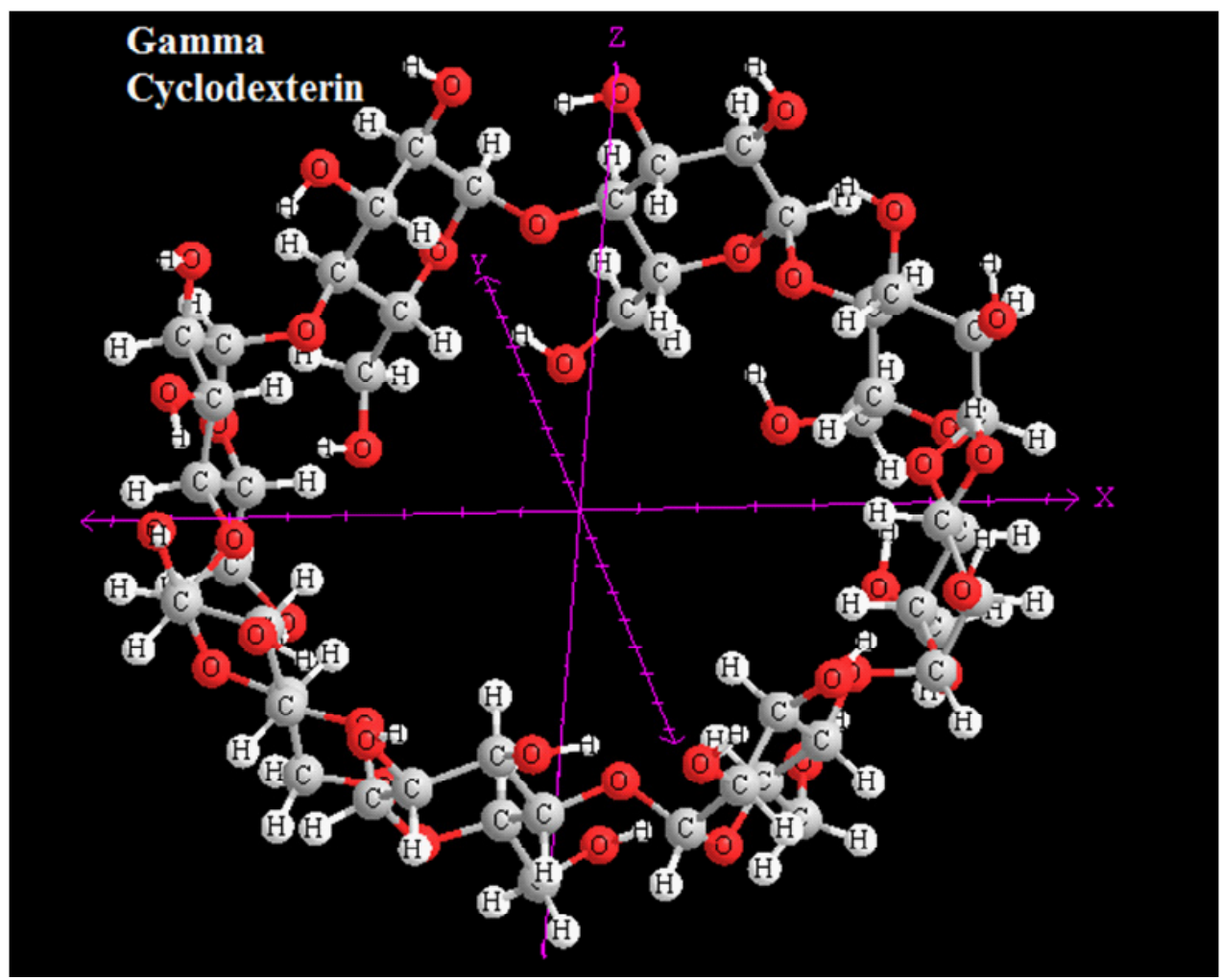

Fig. 2: Optimized of gamma cyclodexterin

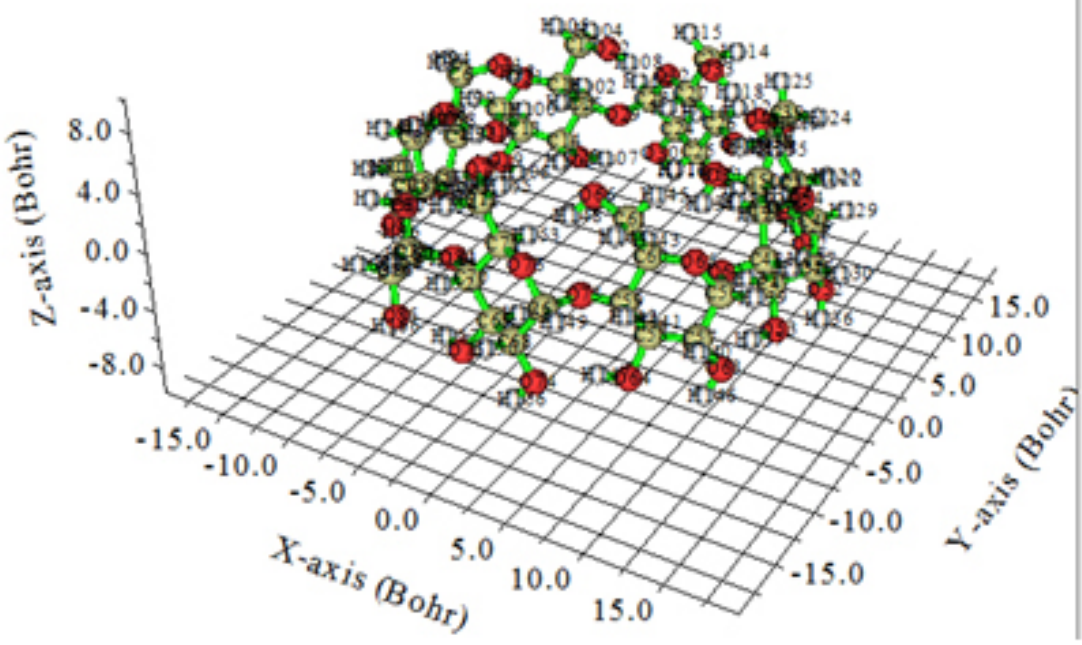

\begin{tabular}{|c|}
\hline Right \\
\hline Zoom in \\
\hline Zoom out \\
\hline Reset view \\
\hline Save picture \\
\hline Show labels \\
Show axis \\
Bonding threshold \\
\hline$-\square$ \\
\hline
\end{tabular}

Ratio of atomic size

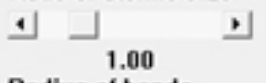

Radius of bonds 1」 $\rfloor_{0.20} \quad$ Size of atomic labels $4 \perp$ Orbitals:

None. П Isovalue

Fig. 3: The gamma $C D$ versus Cartesian orientation 


\section{RESULT AND DISCUSSION}

This study mainly focuses on the magnetic properties of $\mathrm{Fe}_{2} \mathrm{O}_{1}$ in a non-bonded system with Cyclodextrin ( $\alpha$ and $\gamma$ ). Part of the systems including $\mathrm{Fe}_{3} \mathrm{O}_{4} @ \alpha, \gamma$-Cyclodextrin nanoparticles have been considered in this work. It has been exhibited that the $\mathrm{Fe}_{3} \mathrm{O}_{4} @(7,7)$ and $\mathrm{Fe}_{3} \mathrm{O}_{4} @(10,5)$ and $\mathrm{Fe}_{3} \mathrm{O}_{4} @$ $(9,0)$ have physical and chemical properties close to $\mathrm{Fe}_{3} \mathrm{O}_{4} @ \alpha$-Cyclodextrin and as well as the $\mathrm{Fe}_{3} \mathrm{O}_{4}$

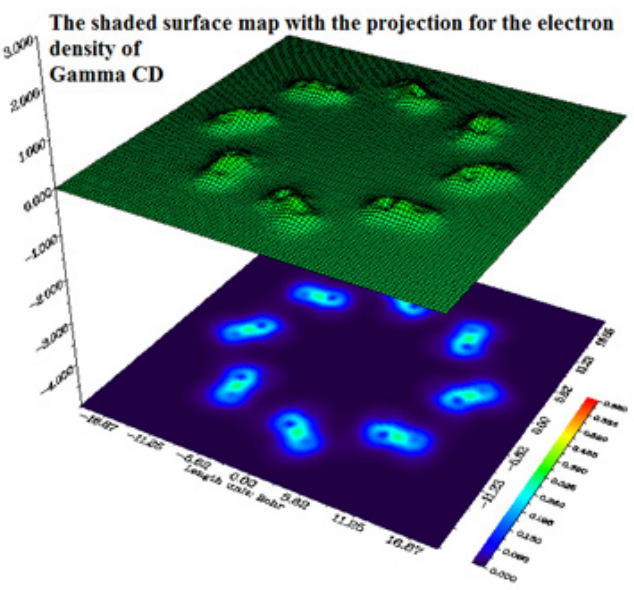

Fig. 4: The Shaded map of electron density for Gamma cyclodexterin
$@(8,8)$ and $\mathrm{Fe}_{3} \mathrm{O}_{4} @(11,6)$ and $\mathrm{Fe}_{3} \mathrm{O}_{4} @(10,0)$ are close to $\mathrm{Fe}_{3} \mathrm{O}_{4} @ \gamma$-Cyclodextrin.

The data are shown in tables 1-6 and figures 1-7 for a non-bonded interaction of the $\mathrm{Fe}_{3} \mathrm{O}_{4}$ with Gamma CD and various nanotubes.

This work has been modeled with QM/MM method and the calculations are carried out with the Advanced DFT methods. Gaussian 2009 and a HyperChem professional release 7.01 programs are used for the additional calculations. For non-covalent interactions between $\mathrm{Fe}_{3} \mathrm{O}_{4}$ and Cyclodextrins, the B3LYP method is unable to describe van der Waals by medium-range interactions. Therefore, the ONIOM methods including 3 levels of 1-high calculation $(H)$, 2-medium calculation (M), and 3-low calculation (L) have been performed in our study for calculating the non-bonded interactions between $\mathrm{Fe}_{3} \mathrm{O}_{4}$ and Cyclodextrins.

The ab-initio and DFT methods are used for the model system of the ONIOM layers and the semi empirical methods of pm3mm (including pseudo=lanl2) and Pm6 are used for the medium and low layers, respectively.

B3LYP and the most other popular and widely used functional are insufficient to illustrate

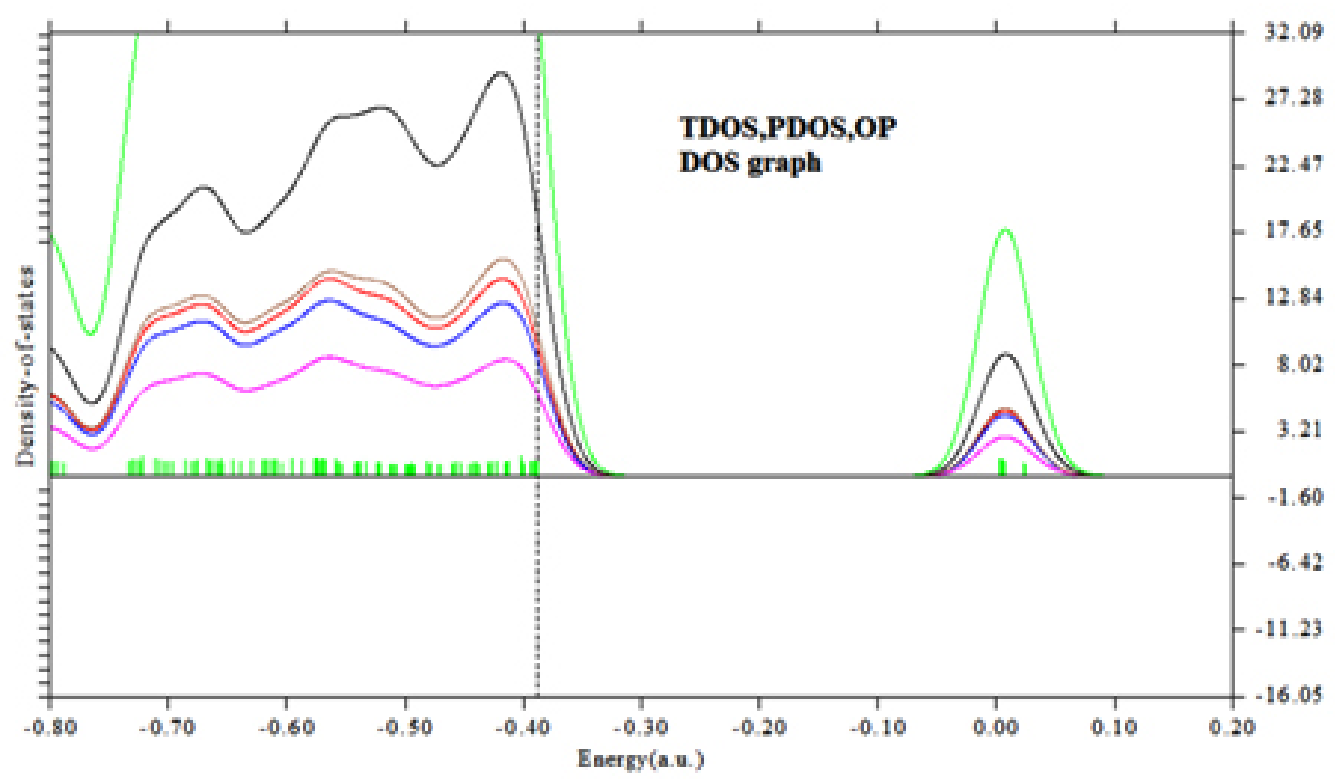

Fig. 5: TDOS, PDOS, OPDOS graph for $\mathrm{Fe}_{3} \mathrm{O}_{4} @$ GammaCD 


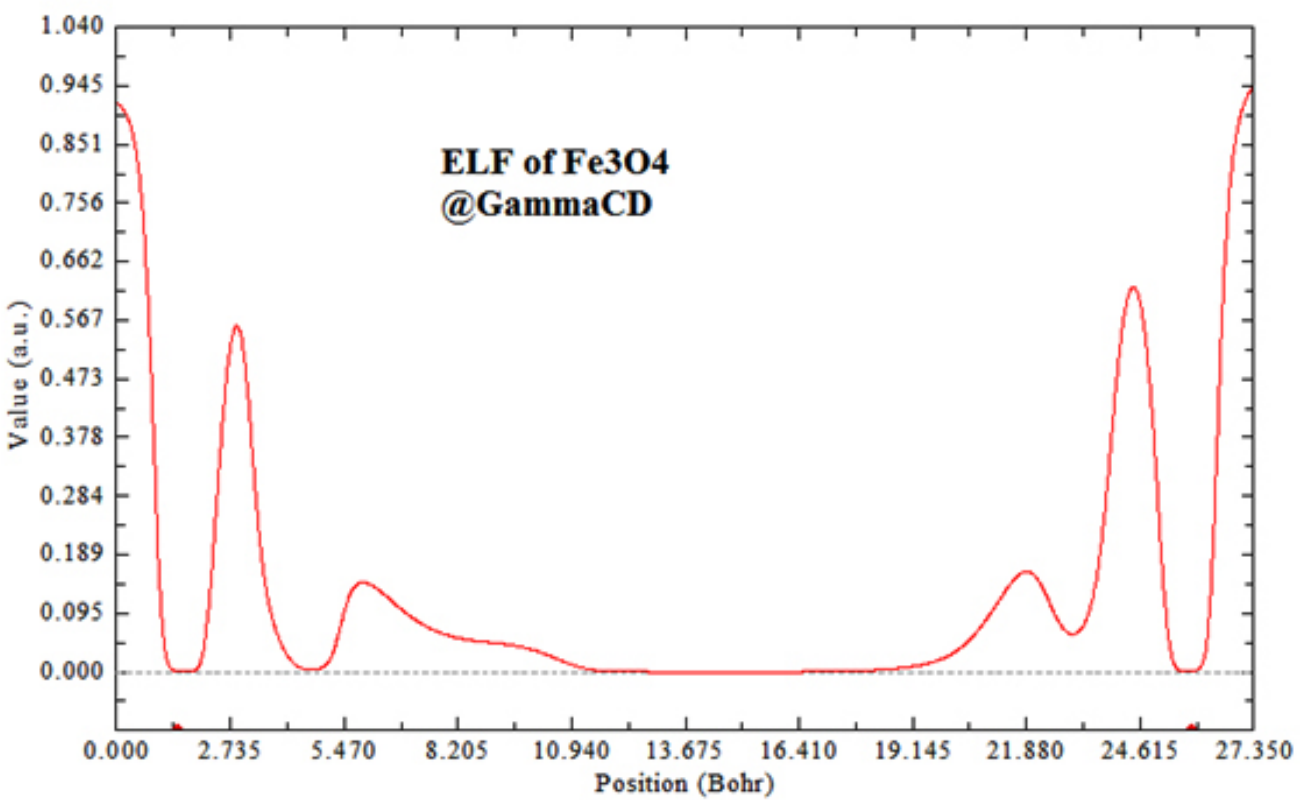

Fig. 6: Electron Localization Function of $\mathrm{Fe}_{3} \mathrm{O}_{4} @$ Gamma Cyclodexterin

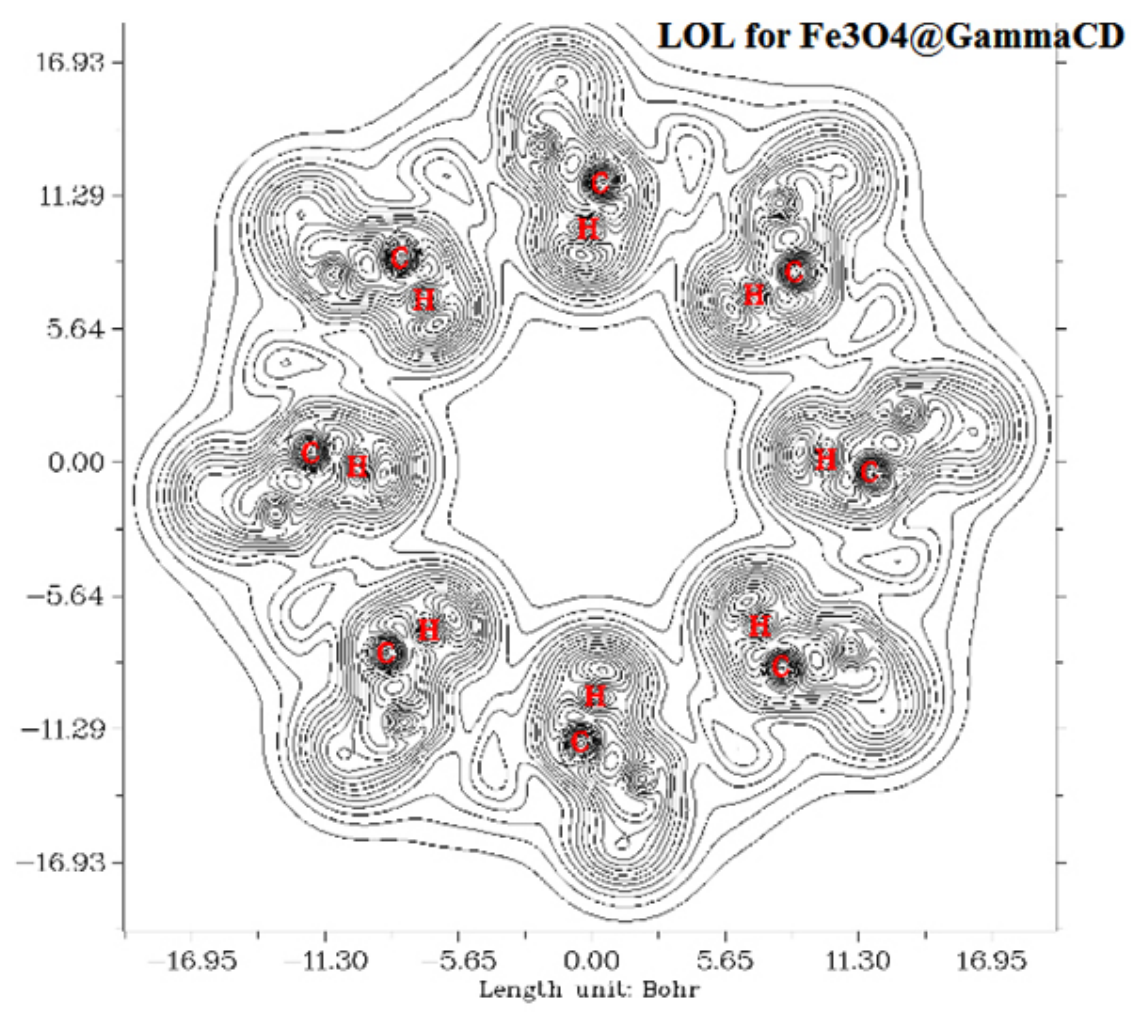

Fig. 7: Localized orbital Locator for $\mathrm{Fe}_{3} \mathrm{O}_{4} @(7,7)$ SWCNTs 
the exchange and correlation energy for distant nonbonded medium-range systems correctly. Moreover, some recent studies have shown that inaccuracy for the medium-range exchange energies leads to large systematic errors in the prediction of molecular properties ${ }^{168-170}$.

Geometry optimizations and electronic structure calculations have been carried out using the m06 (DFT) functional. This approach is based on an iterative solution of the Kohn-Sham equation ${ }^{171}$ of the density functional theory in a plane-wave set with the projector-augmented wave pseudo-potentials. The Perdew-Burke-Ernzerhof (PBE) ${ }^{172}$ exchangecorrelation $(X C)$ functional of the generalized gradient approximation (GGA) is also used. The optimizations of the lattice constants and the atomic coordinates are made by the minimization of the total energy.

The charge transfer and electrostatic potential-derived charge were also calculated using the Merz-Kollman-Singh chelp or chelpG ${ }^{173-176}$ the charge calculation methods based on molecular electrostatic potential (MESP) fitting are not wellsuited for treating larger systems whereas some of the innermost atoms are located far away from the points at which the MESP is computed. In such a condition, variations of the innermost atomic charges will not head towards a significant change of the MESP outside of the molecule, meaning that the accurate values for the innermost atomic charges are not well-determined by MESP outside the molecule . The representative atomic charges for molecules should be computed as average values over several molecular conformations.

A detailed overview of the effects of the basis set and the Hamiltonian on the charge distribution can be found in references ${ }^{175-177}$. The charge density proûles in this study has been extracted from ûrst-principles calculation through an averaging process as described in reference ${ }^{175-177}$. The interaction energy for capacitor was calculated in all items according to the equation as follows:

$$
\Delta E_{S}(\mathrm{eV})=\left\{E_{C}-\left(\begin{array}{c}
\sum_{i=1}^{n}(\mathrm{Fe} 304-\text { Cyclodextrin }(\alpha \text { and } \gamma))_{i} \\
\left.+\sum_{i=1}^{n}(F e 304-\text { Cyclodextrin }(\alpha, \text { and } \gamma))_{i}\right)_{j}
\end{array}\right)\right\}
$$

Where the " $\Delta E_{s}$ " is the stability energy.

The electron density (Both of Gradient norm \& Laplacian), value of orbital wave-function, electron spin density, electrostatic potential from nuclear atomic charges, electron localization function (ELF), localized orbital locator (LOL defined by Becke \& Tsirelson), total electrostatic potential (ESP), as well as the exchange-correlation density, correlation hole and correlation factor, and the average local ionization energy using the Multifunctional Wavefunction analyzer have also been calculated in this study ${ }^{35-37}$. The contour line map was also drawn using the Multiwfn software ${ }^{35,36}$. The solid lines indicate positive regions, while the dash lines indicate negative regions. The contour line corresponding to VdW surface (electron density $=0.001$ a.u., which is defined by R. F. W Bader) is plotted in this study. This is specifically useful to analyze distribution of electrostatic potential on VdW surface. Such a contour line has also been plotted in gradient line and vector field map by the same option. The relief map was used to present the height value at every point. Shaded surface map and shaded surface map with projection are used in our representation of height value at each situation ${ }^{35-37}$.

Electrical properties can be obtained from changes in the non-bonded interaction situations. Electron densities, energy densities, Potential energy densities, ELF, LOL, Ellipticity of electron density , eta index and ECP for $\mathrm{Fe}_{3} \mathrm{O}_{4}$ - Cyclodextrin $\left(\alpha\right.$, and $\gamma$ ) shell and $\mathrm{Fe}_{3} \mathrm{O}_{4} @(7,7), \mathrm{Fe}_{3} \mathrm{O}_{4} @(10,5)$, $\mathrm{Fe}_{3} \mathrm{O}_{4} @(9,0), \mathrm{Fe}_{3} \mathrm{O}_{4} @(8,8), \mathrm{Fe}_{3} \mathrm{O}_{4} @(11,6)$ and $\mathrm{Fe}_{3} \mathrm{O}_{4} @(10,0)$ were calculated for each of simulation (Table1-6).

We believe that this research has a great potential for the development of new multifunctional catalysts with high reactivity and selectivity. Another interesting development is using the SWCNTs on magnetic nanoparticles that enable effective removal of transition metal based catalysts from important pharmaceutical products in drug synthesis. This approach should find relevant industrial applications in biopharmaceutical, food additives, fragrances and other sectors. 


\section{REFERENCES}

1. Veiseh, O.; Gunn, J.W.; Zhang, M. Advanced Drug Delivery Reviews, 2010. 62, 3, 284304.

2. Yang, L.; Ren, X.; Tang, F.; Zhang, L.; Biosensors and Bioelectronics, 2009, 25, 4, 889-895.

3. Ripka, $\mathrm{P}$, Journal of Magnetism and Magnetic Materials, 2000, 215, 735-739.

4. Wilhelm, C.; Gazeau, F. Biomaterials, 2008, 29(22), 3161-3174.

5. Jain, T.K.; Foy, S.P.; Erokwu, B.; Dimitrijevic, S.; Flask, C.A.; Labhasetwar, V. Biomaterials, 2009, 30(35), 6748-6756.

6. Ma, Ming; Zhang, Yu; Guo, Zhir4.ui; GU, Ning, Nanoscale Research Letters, 2013, 8 (1), 16.

7. Massart, R.; IEEE transactions on magnetics, 1981, 17(2), 1247-1248

8. Sunggyu Lee Encyclopedia of Chemical Processing CRC Press, 2006, ISBN 0-82475563-4

9. Agrawal, A.; Sathe, T.; Nie, S.; Journal of Agricultural and Food Chemistry, 2007, 55(10), 3778-3782.

10. Liang, X.; Xu, K.; Xu, J.; Chen, W.; Shen, H. Liu, J. Journalof Magnetism and Magnetic Materials, 2009, 32(12), 1885-1888.

11. Shan, Z.; Wu, Q.; Wang, X. Analytical Biochemistry, 2010, 398, 1, 120-122.

12. Shen, Y. F.; Tang, J.; Nie, Z. H. ; Wang, Y. D.; Ren, Y.; Zuo, L.Separation and Purification Technology, 2009, 68, 3, 312-319.

13. Valter, Ström; Richard T.; Olsson, K. V. Rao. J. Mater. Chem, 2010, 20, 4168-4175

14. Mei Fang, Valter Ström, Richard T. Olsson, Lyubov Belova, K. V. Rao, Rapid mixing: Appl. Phys. Lett.2011, 99, 222501

15. Shin, S.; Jang, J.; Chem. Commun.2007, 41, 4230.

16. Oliveira, L.C.A.; Petkowicz, D.I.; Smaniotto, A.; Pergher, S.B.C.; Water Res.2004, 38; 3699.

17. Hu, J.; Lo, M.C.; Chen, G.H.; Water Sci. Technol.2004, 50,139.

18. Hu, J.; Chen, G.; Lo, I.M.C. Water Res. 2005, 39, 4528.

19. Yavuz, C.T.; Mayo, J.T.; Yu, W.W.; Prakash, A.; Falkner, J.C.; Yean, S.; Cong, L.; Shipley, H.J.;
Kan, A. ; Tomson, M. ; Natelson, D.; Colvin, V.L.; Science,2006, 314,964.

20. Hai, B.; Wu, J.; Chen, X. ; Protasiewicz, J.D.; Scherson, D.A. ; Langmuir,2005, 213104.

21. Hu, J.; Lo, M.C.; Chen, G.H.; Sep. Purif. Technol.2007, 58, 76.

22. Chang, Y.C.; Chen, D.H.; J. Colloid Interface Sci.2005, 283,446.

23. Liu, J.F.; Zhao, Z.S.; Jiang, G.B.; Environ. Sci. Technol.2008, 42, 6949.

24. Yantasee, W.; Warner, C.L.; Sangvanich, T.; Addleman, R.S.; Carter, T.G. ; Wiacek, R.J.; Fryxell, G.E.; Timchalk, C.; Warner, M.G.; Environ. Sci. Technol.2007, 41, 5114.

25. Zhou, Y.T.; Nie, H.L.; Branford-White, C.; He, Z.Y. J. Colloid Interface Sci.2009, 33029.

26. Liu, Q.; Xu, Z.; Finch, J.A.; Egerton, R. Chem. Mater. 1998, $10,3936$.

27. Lu, C.W.; Hung, Y.; Hsiao, J.K.; Yao, M.; Chung, T.H.; Lin, Y.S.; Wu, S.H.; Hsu, S.C.; Liu, H.M.; Mou, C.Y.; Yang, C.S.; Huang, D.M.; Chen, Y.C.; Nano Lett.2007, 7, 149.

28. Ashtari, P. He, X.X.; Wang, K.; Gong, P.; Talanta ,2005,67,548.

29. Villiers, A. Compt. Rend. 1891, 112, 536539.

30. Schardinger, F.; Zentralbl. Bakteriol. Abt. //1911, 29, 188-197; (b) Freudenberg, K.; Schaaf, E. Dumpert, G.; Ploetz, T. Naturwissenschaften, 1937, 27, 850-853

31. Wenz, G. Angew. Chem. Int. Ed. Engl. 1994, 33, 803-822

32. Ueno, A. Supramol. Sci. 1996, 3, 31-36

33. Skidmore-Roth, L.; (Ed.). Mosby's Nursing Drug Reference, 2010, (23rd ed.). St. Louis, MO: Mosby Elsevier

34. Paganelli, CV.; Solomon AK .J Gen Physiol, 1957, 41, 259-277

35. Lu, T.; Chen, F. Acta Chim. Sinica,2011, 69, 2393-2406.

36. Lu, T.; Chen, F.; J. Mol. Graph. Model. 2012, 38: 314-323.

37. Lu, T.; Chen, F.; J. Comp. Chem. 2012,33580592.

38. Bader, R.F.W. Atoms in Molecule: A quantum Theory (Oxford Univ. press, Oxford, (1990).

39. Becke and Edgecombe J. Chem. Phys., 1990, 
92, 5397.

40. Savin, A.; Angew. Chem. Int. Ed.Engl., 1992, 31, 187.

41. Tsirelson, V.G.; Abramov. Yu.A. Chem. Phys. Lett, 2002, 351, 142-148.

42. Schmider, H.L.; Becke, A.D. J Mol Struct (Theochem), 2000, 527:51 50.

43. Jacobsen Can. J. Chem., 2008, 86(7), 695.

44. Jamali,Z.; Monajjemi,M.; J. Comput. Theor. Nanosci.2016, 13, 643-651.

45. Mirzaei ,R.; Ziglari ,A.; Elsagh,A.; Esmkhani,R.; Monajjemi, M.; J. Comput. Theor. Nanosci.2016, 13, 899-908.

46. Monajjemi, M.; Lee, V.S.; Khaleghian, M.; B. Honarparvar, B.; F. Mollaamin, F. J. Phys. Chem C. 2010, 114, 15315

47. Monajjemi, M. Struct Chem. 2012, 23,551580

48. Monajjemi, M.; Chegini, H.; Mollaamin, F.; Farahani, P. Fullerenes, Nanotubes, and Carbon Nanostructures. 2011, 19, 469-482

49. Monajjemi, M .; Afsharnezhad ,S.; Jaafari , M.R.; Abdolahi ,T.; Nikosade ,A.; Monajemi ,H.; Russian Journal of physical chemistry A, 2007, 2,1956-1963

50. Monajjemi, M.; Baei, M.T.; Mollaamin, F. Russian Journal of Inorganic Chemistry. 2008, 53 (9), 1430-1437

51. Monajjemi, M.; Rajaeian, E.; Mollaamin, F.; Naderi, F.; Saki, S. Physics and Chemistry of Liquids. 2008, 46 (3), 299-306

52. Monajjemi, M.; Boggs, J.E. J. Phys. Chem. A, 2013, 117, 1670 "1684

53. Mollaamin, F.; Monajjemi, M, Journal of Computational and Theoretical Nanoscience. 2012, 9 (4) 597-601

54. Monajjemi, M.; Khaleghian, M, Journal of Cluster Science. 2011, 22 (4) ), 673-692 318

55. Nafisi, S.; Monajemi, M.; Ebrahimi, S. Journal of Molecular Structure. 2004,705 (3) 35-39

56. Fazaeli, R.; Monajjemi, M.; Ataherian, F.; Zare, K. Journal of Molecular Structure: THEOCHEM.2002, 581 (1), 51-58

57. Monajjemi, M.; Razavian, M.H.; Mollaamin,F.; Naderi,F.; Honarparvar,B.; Russian Journal of Physical Chemistry A , 2008 , 82 (13), 22772285

58. Monajjemi, M.; Seyed Hosseini, M.; Mollaamin, F. Fullerenes, Nanotubes, and Carbon Nanostructures. 2013, 21, 381-393
59. Monajjemi, M.; Faham, R.; Mollaamin, F. Fullerenes, Nanotubes, and Carbon Nanostructures, 2012 20, 163-169

60. Mollaamin, F.; Najafi, F.; Khaleghian, M.; Khalili Hadad, B.; Monajjemi, M. Fullerenes, Nanotubes, and Carbon Nanostructures, 2011 19, 653-667

61. Mollaamin, F.; Baei, MT.; Monajjemi, M.; Zhiani, R.; Honarparvar, B.; Russian Journal of Physical Chemistry A, Focus on Chemistry, 2008, 82 (13), 2354-2361

62. Monajjemi, M. Chemical Physics. 2013, 425, 29-45

63. Monajjemi, M.; Heshmat, M.; Aghaei, H.; Ahmadi, R.; Zare, K. Bulletin of the Chemical Society of Ethiopia, 2007, 21 (1)

64. Monajjemi, M.; Honarparvar, B. H. ; Haeri, H. ; Heshmat ,M.; Russian Journal of Physical Chemistry C. 2006, 80(1):S40-S44

65. Monajjemi, M.; Ketabi, S.; Amiri, A. Russian Journal of Physical Chemistry, 2006, 80 (1), S55-S62

66. Yahyaei, H.; Monajjemi, M.; Aghaie, H.; K. Zare, K. Journal of Computational and Theoretical Nanoscience. 2013, 10(10), 2332-2341

67. Mollaamin, F.; Gharibe, S.; Monajjemi, M. Int. J. Phy. Sci, 2011, 6, 1496-1500

68. Monajjemi, M.; Ghiasi, R.; Seyed Sadjadi, M.A. Applied Organometallic Chemistry,2003, 17(8), 635-640

69. Monajjemi, M.; Wayne Jr, Robert. Boggs, J.E. Chemical Physics. 2014, 433, 1-11

70. Monajjemi, M.; Sobhanmanesh, A.; Mollaamin, F. Fullerenes, Nanotubes, and Carbon Nanostructures, 2013, 21 47-63

71. Monajjemi, M.; Mollaamin, F. Journal of Computational and Theoretical Nanoscience, 2012, 9 (12) 2208-2214

72. Monajjemi, M.; Honarparvar, B.; Nasseri, S. M. .; Khaleghian M. Journal of Structural Chemistry. 2009, 50(1), 67-77

73. Monajjemi, M.; Aghaie, H.; Naderi, F. Biochemistry (Moscow).2007, 72 (6), 652657

74. Ardalan, T.; Ardalan, P.; Monajjemi, M. Fullerenes, Nanotubes, and Carbon Nanostructures, 2014, 22: 687-708

75. Mollaamin, F.; Monajjemi, M.; Mehrzad, J. Fullerenes, Nanotubes, and Carbon 
Nanostructures. 2014, 22: 738-751

76. Monajjemi, M.; Najafpour, J.; Mollaamin, F. Fullerenes, Nanotubes, and Carbon Nanostructures. 2013, 21(3), 213-232

77. Monajjemi, M.; Karachi, N.; Mollaamin, F. Fullerenes, Nanotubes, and Carbon Nanostructures, 2014, 22: 643-662

78. Yahyaei, H.; Monajjemi, M. Fullerenes, Nanotubes, and Carbon Nanostructures.2014, 22(4), 346-361

79. Monajjemi, M. Falahati, M.; Mollaamin, F.; Ionics, 2013, 19, 155-164

80. Monajjemi, M.; Mollaamin, F. Journal of Cluster Science, 2012, 23(2), 259-272

81. Tahan, A.; Monajjemi, M. Acta Biotheor, 2011, 59, 291-312

82. Lee, V.S.; Nimmanpipug, P.; Mollaamin, F.; Kungwan, N.; Thanasanvorakun, S.; Monajjemi, M. Russian Journal of Physical Chemistry A, 2009, 83(13), 2288-2296

83. Monajjemi, M.; Heshmat, M.; Haeri, HH, Biochemistry (Moscow), 2006, 71 (1), S113S122

84. Monajjemi, M.; Yamola, H.; Mollaamin, F. Fullerenes, Nanotubes, and Carbon Nanostructures, 2014, 22, 595-603

85. Mollaamin, F.; Layali, I.; Ilkhani A. R.; Monajjemi, M. African Journal of Microbiology Research .2010, 4(24) 2795-2803

86. Mollaamin, F.; Shahani poor, p K. .; Nejadsattari, T. ; Monajjemi, M. African Journal of Microbiology Research. 2010, 4(20) 2098-2108

87. Monajjemi, M.; Ahmadianarog, M. Journal of Computational and Theoretical Nanoscience. 2014, 11(6), 1465-1471

88. Monajjemi, M.; Jafari Azan, M.; Mollaamin, F. Fullerenes, Nanotubes, and Carbon Nanostructures.2013, 21(6), 503-515

89. Mollaamin, F.; Monajjemi, M. Physics and Chemistry of Liquids .2012, 50(5), 596-604

90. Monajjemi, M.; Khosravi, M.; Honarparvar, B.; Mollaamin, F.; International Journal of Quantum Chemistry, 2011, 111, 2771-2777

91. Khaleghian, M.; Zahmatkesh, M.; Mollaamin, F.; Monajjemi, M. Fullerenes, Nanotubes, and Carbon Nanostructures, 2011, 19(4): 251-261

92. Monajjemi, M.; Baheri, H.; Mollaamin, F. Journal of Structural Chemistry.2011 52(1),
54-59

93. Mahdavian, L.; Monajjemi, M.; Mangkorntong, N. Fullerenes, Nanotubes and Carbon Nanostructures, 2009, 17 (5), 484-495

94. Monajjemi, M., Mahdavian, L., Mollaamin, F. Bull. Chem. Soc. Ethiop. 2008, 22(2), 277286

95. Monajjemi, M.; Afsharnezhad, S, Jaafari, M.R..; Mirdamadi, S..; Mollaamin, F..; Monajemi, H. Chemistry .2008, 17 (1), 55-69

96. Monajjemi, M.; Mollaamin, F.; Gholami, M. R.; Yoozbashizadeh, H.; Sadrnezhaad, S.K.; Passdar, H.; Main Group Metal Chemistry, 2003, 26 (6), 349-361

97. Monajjemi, M.; Azad ,MT.; Haeri, HH.; Zare, K.; Hamedani, Sh.; Journal of Chemical Research-s.2003, 8: 454-456

98. Monajjemi, M.; Najafpour, J. Fullerenes, Nanotubes, and Carbon Nanostructures, 2014, 22(6): 575-594

99. Monajjemi, M.; Noei, M.; Mollaamin, F. Nucleosides, Nucleotides and Nucleic Acids. 2010 29(9):676-683

100. Ghiasi, R.; Monajjemi, M. Journal of Sulfur Chemistry .2007, 28 $(\underline{5)}$, 505-511

101. Monajjemi, M.; Ghiasi, R.; Abedi, A. Russian Journal of Inorganic Chemistry.2005, 50(3), 382-388

102. Monajjemi, M. .; Naderi, F.; Mollaamin, F.; Khaleghian, M. J. Mex. Chem. Soc. 2012, 56(2), 207-211

103. Monajjemi, M.; Farahani, N.; Mollaamin, F. Physics and Chemistry of Liquids, 2012, 50(2) 161-172

104. Monajjemi, M.; Seyed Hosseini, M. Journal of Computational and Theoretical Nanoscience .2013, 10 (10), 2473-2477

105. Monajjemi , M.; Honaparvar, B.; Khalili Hadad ,B.; Ilkhani ,AR.; Mollaamin, F. African Journal of Pharmacy and Pharmacology .2010, 4(8), $521-529$

106. Monajjemi, M. Theor Chem Acc, 2015, 134:77 DOI 10.1007/s00214-015-1668-9

107. Monajjemi, M. Journal of Molecular Modeling , 2014, 20, 2507

108. Monajjemi, M.; Honarparvar, B.; Monajemi, $\mathrm{H}$.; Journal of the Mexican Chemical Society, 2006, 50 (4), 143-148

109. Monajjemi, M.; Khaleghian, M.; Mollaamin, F. Molecular Simulation. 2010, 36(11), 865- 
110. Ilkhani, Ali R.; Monajjemi, M. Computational and Theoretical Chemistry.2015 1074, 19-25

111. Monajjemi, M. Biophysical Chemistry. 2015 207,114-127

112. Monajjemi, M., Moniri, E., Panahi, H.A , Journal of Chemical and Engineering Data.2001, 1249-1254.

113. Mollaamin, F; Najafpour, J.; Ghadami, S.; Ilkhani, A. R.; Akrami, M. S.; Monajjemi, M. Journal of Computational and Theoretical Nanoscience. 11 (5), 1290-1298

114. Monajjemi, M.; Ghiasi, R.; Ketabi, S.; Passdar, H.; Mollaamin, F. Journal of Chemical Research . 2004, 1, 11.

115. Monajjemi, M.; Heshmat, M.; Haeri, H.H. Biochemistry (Moscow).2006, 71, 113-122

116. Monajjemi, M.; Heshmat, M.; Aghaei, H.;Ahmadi, R.; Zare, K. Bulletin of the Chemical Society of Ethiopia. 2007, 21, 111-116

117. Monajjemi, M., Kharghanian, L., Khaleghian, M., Chegini, H. Fullerenes Nanotubes and Carbon Nanostructures.2014, 22,(8), 0.1080/1536383X.2012.717563

118. Sarasia, E.M.; Afsharnezhad, S.; Honarparvar, B.; Mollaamin, F.; Monajjemi, M.Physics and Chemistry of Liquids. 2011, 49 (5), 561-571

119. Amiri, A.; Babaeie, F.; Monajjemi, M. Physics and Chemistry of Liquids. 2008, 46(4), 379389

120. Monajjemi, M.; Heshmat, M.; Haeri, H.H.; Kaveh, F. Russian Journal of Physical Chemistry A, 2006, 80(7), 1061-1068

121. Monajjemi, M.; Moniri, E.; Azizi, Z.; Ahmad Panahi, H. Russian Journal of Inorganic Chemistry. 2005, 50 (1), 40-44

122. Jalilian,H.; Monajjemi, M. Japanese Journal of Applied Physics. 2015,54 (8), 08510

123. Mollaamin, F.; Monajjemi, M. Journal of Computational and Theoretical Nanoscience.2015, 12(6), 1030-1039

124. Felegari, Z.; Monajjemi, M. Journal of Theoretical and Computational Chemistry. 2015, 14(3), 1550021

125. Shojaee, S., Monajjemi, M. Journal of Computational and Theoretical Nanoscience. 2015, 12(3), 449-458

126. Esmkhani, R.; Monajjemi, M. Journal of Computational and Theoretical Nanoscience.
2015. 12(4), 652-659

127. Monajjemi, M., Seyedhosseini, M., Mousavi, M., Jamali, Z, Journal of Computational and Theoretical Nanoscience. 2015, 23(3), 239244

128. Ghiasi, R.; Monajjemi, M.; Mokarram, E.E.; Makkipour, P. Journal of Structural Chemistry. 2008, 4(4), 600-605

129. Mahdavian, L.; Monajjemi, M. Microelectronics Journal. 2010, 41(2-3), 142-149

130. Monajjemi, M.; Baie, M.T.; Mollaamin, F. Russian Chemical Bulletin.2010, 59(5), 886889

131. Bakhshi, K.; Mollaamin, F.; Monajjemi, M. Journal of Computational and Theoretical Nanoscience. 2011, 8(4), 763-768

132. Darouie, M.; Afshar, S.; Zare, K., Monajjemi, M. journal of Experimental Nanoscience.2013, 8(4), 451-461

133. Amiri, A.; Monajjemi, M.; Zare, K.; Ketabi, S. Physics and Chemistry of Liquids. 2006, 44(4), 449-456.

134. Zonouzi, R.;Khajeh, K.; Monajjemi, M.; Ghaemi, N. Journal of Microbiology and Biotechnology. 2013, 23(1), 7-14

135. Ali R. Ilkhani.; Majid Monajjemi, Computational and Theoretical Chemistry.2015, 10(74) 19-25

136. Tahan, A.; Mollaamin, F.; Monajjemi, M. Russian Journal of Physical Chemistry $A$, 2009, 83 (4), 587-597

137. Khalili Hadad, B.; Mollaamin, F.; Monajjemi, M, Russian Chemical Bulletin,2011, 60(2):233236

138. Mollaamin, F.; Monajjemi, M.; Salemi, S.; Baei, M.T. Fullerenes Nanotubes and Carbon Nanostructures, 2011, 19(3), 182-196

139. Mollaamin, F.; Shahani Pour.; K., Shahani Pour, K.; ilkhani, A.R.; Sheckari, Z., Monajjemi, M Russian Chemical Bulletin , 2012 , 61(12), 2193-2198

140. Shoaei, S.M.; Aghaei, H.; Monajjemi, M.; Aghaei, M. Phosphorus, Sulfur and Silicon and the Related Elements. 2014, 189(5) 652660

141. Mehrzad, J., Monajjemi, M., Hashemi, M , Biochemistry (Moscow).2014, 79 (1), 31-36

142. Moghaddam, N.A., Zadeh, M.S., Monajjemi, M. Journal of Computational and Theoretical Nanoscience , 2015 , 12 (3), doi:10.1166/ 
jctn.2015.3736

143. Joohari, S.; Monajjemi, M, Songklanakarin Journal of Science and Technology, 2015, 37(3):327

144. Rajaian, E., Monajjemi, M., Gholami, M.R, Journal of Chemical Research - Part S, 2002, 6(1), 279-281

145. Ghassemzadeh, L., Monajjemi, M., Zare, K, Journal of Chemical Research - Part S, 2003, 4, 195-199

146. Mehdizadeh Barforushi,M.; Safari,S.; Monajjemi,M.; J. Comput. Theor. Nanosci. 2015, 12, 3058-3065.

147. Mollaamin,F.; Ilkhani,A.; Sakhaei,N.; Bonsakhteh,B.; Faridchehr,A.; Tohidi,S.; Monajjemi,M.; J. Comput. Theor. Nanosci. 2015, 12, 3148-3154.

148. Rahmati,H.; Monajjemi,M.; J. Comput. Theor. Nanosci.2015, 12, 3473-3481.

149. Tarlani Bashiz,R.; Monajjemi,M.; J. Comput. Theor. Nanosci.2015, 12, 3808-3816.

150. Mehrabi Nejad,A.; Monajjemi,M.; J. Comput. Theor. Nanosci. 2015, 12, 3902-3910.

151. Monajjemi,M *.; Bagheri,S.; Moosavi,M.S..; Moradiyeh,N.; Zakeri,M.; Attarikhasraghi,N.; Saghayimarouf, N.; Niyatzadeh, G. ; Shekarkhand,M.; Mohammad S. Khalilimofrad, Ahmadin,H.; Ahadi,M.; Molecules 2015, 20, 21636-21657;

152. Shabanzadeh,E.; Monajjemi,M.; J. Comput. Theor. Nanosci.2015, 12, 4076-4086.

153. Elsagh,A.: Jalilian,H.; Kianpour,E.; Sadat Ghazi Mokri,H.; Rajabzadeh,M.; Moosavi,M.S.; Ghaemi Amiri,F.; Monajjemi,M.; J. Comput. Theor. Nanosci. 2015, 12, 4211-4218.

154. Faridchehr,A.; Rustaiyan, A.; Monajjemi,M.; J. Comput. Theor. Nanosci.2015, 12, 43014314.

155. Tohidi,S.; Monajjemi,M.; Rustaiyan,A.; J. Comput. Theor. Nanosci. 2015, 12, 43454351.

156. Ali Akbari Zadeh,M.; Lari,H.; Kharghanian,L.; Balali,E.; Khadivi,R.;Yahyaei,H.; Mollaamin,F.; Monajjemi,M.; J. Comput. Theor. Nanosci. 2015, 12, 4358-4367.

157. Dezfooli,S.; Lari,H.; Balali,E.; Khadivi,R.; Farzi,F.; Moradiyeh,N.; Monajjemi,M.; J. Comput. Theor. Nanosci. 2015, 12, 44784488.

158. Jalilian,H.: Sayadian,M.; Elsagh,A.; Farzi,F.;
Moradiyeh,N.; Samiei Soofi,N.; Khosravi,S.; Mohammadian,N.T.; Monajjemi,M.;J. Comput. Theor. Nanosci.2015, 12, 4785-4793.

159. Farzi,F.; Bagheri,S.; Rajabzadeh,M.; Sayadian,M.; Jalilian,H.; Moradiyeh,N.; Monajjemi,M.; J. Comput. Theor. Nanosci. 2015, 12, 4862-4872.

160. Monajjemi,M.; Nayyer T. Mohammadian J. Comput. Theor. Nanosci. 2015, 12, 48954914.

161. Monajjemi, M., Chahkandi, B. Journal of Molecular Structure: THEOCHEM, 2005, 714 (1), 28, 43-60.

162. Joohari*,S.; Monajjemi, M.; Bulgarian Chemical Communications,2015, 47(2) 631 $-646$.

163. Moradiyeh,N.; Zakeri, M.; Attarikhasraghi,N.; Ahadi,M.; Saghayimarouf ,N.; Niyatzadeh , G.; Mahmoodi ,Z.; Shekarkhand,M.; Ahmadin, H.; Monajjemi,M.; J. Comput. Theor. Nanosci. 2015, 12, 5395-5401.

164. Zawari, M.; Haghighizadeh, M.; Derakhshandeh,M.; Barmaki ,Z.; Farhami,N.; Monajjemi,M.; J. Comput. Theor. Nanosci. 2015, 12, 5472-5478.

165. Sadatchoobeh,S.; Monajjemi,M.; J. Comput. Theor. Nanosci. 2015, 12, 5789-5795.

166. Shadmani ,N.; MehdizadehBarforushi, M.; Shakibayifar, J.; Elsagh,A.; Zare ,K.; Abbasi,Z.; Khalili1 ,M.S.; Ahmadin ,H.; Rajabzadeh,M.; Sayadian,M.; Monajjemi,M.; J. Comput. Theor. Nanosci. 2016, 13, 208-219.

167. Shadmani,N.; Monajjemi,M.; Zare,K.; J. Comput. Theor. Nanosci. 2016, 13, 378387.

168. Grimme, S. Angew Chem Int Ed, 2006, (45), 4460-4464, DOI: 10.1002/anie.200600448.

169. Schreiner, P.R.; Fokin, A. A.; Pascal, R. A Jr.; de Meijere, A. Org. Lett, 2006, (8): 36353638.

170. Zhao, Y.; Truhlar, D.G. Org. Lett, 2006 , (8):5753-5755.

171. Kohn, W.; Sham, LJ. Phys. Rev, 1965, (140) A: 1133-1138.

172. Perdew, J .P. Burke, K.; Phys. Rev. Lett.1996, (77): 3865-3868.

173. Besler, B.H.; Merz, K.M.; Kollman, P.A. J. comp. Chem, 1990, (11): 431-439,

174. Chirlian, L.E.; Francl, M.M. J.comp.chem, 1987, (8): 894-905, 
175. Brneman, G.M, Wiberg, K.B. J. Comp Chem, 1990, (11): 361

176. Martin, F.; Zipse, H. J Comp Chem. 2005, (26):
97 - 105.

177. Balderchi, A.; Baroni, S.; Resta, R. Phys. Rev. Lett, 1998, (61): 173. 